\title{
Effectiveness of a Motivation and Practical Skills Development Methods on the Oral Hygiene of Orphans Children in Kaunas, Lithuania
}

\author{
Greta Markeviciute ${ }^{1}$, Julija Narbutaite ${ }^{2}$ \\ ${ }^{1}$ Snipiskes Medical Center, Vilnius, Lithuania. \\ ${ }^{2}$ Clinic for Preventive and Paediatric Dentistry, Faculty of Odontology, Lithuanian University of Health Sciences, Kaunas, \\ Lithuania.
}

\author{
Corresponding Author: \\ Greta Markeviciute \\ Snipiskes Medical Center \\ Kalvariju 170 LT-08206 Vilnius \\ Lithuania \\ Phone: 862858814 \\ Fax: (8 5) 2375753 \\ E-mail: greta.markeviciute@gmail.com
}

\begin{abstract}
Objectives: The aim of this study was to evaluate the effect of a motivation and practical skills development methods on the oral hygiene of orphans.

Material and Methods: Sixty eight orphans aged between 7 and 17 years from two orphanages in Kaunas were divided into two groups: practical application group and motivation group. Children were clinically examined by determining their oral hygiene status using Silness-Löe plaque index. Questionnaire was used to estimate the oral hygiene knowledge and practices at baseline and after 3 months. Statistical analysis included: Chi-square test $\left(\chi^{2}\right)$, Fisher's exact test, Student's t-test, nonparametric Mann-Whitney test, Spearman's rho correlation coefficient and Kappa coefficient.

Results: All children had a plaque on at least one tooth in both groups: motivation 1.14 (SD 0.51), practical application 1.08 (SD 0.4) $(\mathrm{P}=0.58)$. Girls in both groups showed significantly better oral hygiene than boys $(\mathrm{P}<0.001)$. After 3 months educational program oral hygiene status improved in both groups significantly 0.4 (SD 0.35$)(\mathrm{P}<0.001)$. Significantly better oral hygiene was determined in practical application group 0.19 (SD 0.27) in comparison with motivation group 0.55 (SD 0.32) $(\mathrm{P}<0.001)$. By comparing results of first and second questionnaire surveys on use of soft drinks, the statistically significant decline of their use was in both groups $(\mathrm{P}=0.004)$.

Conclusions: Educational programs are effective in improving oral hygiene, especially when they're based on practical skills training.
\end{abstract}

Keywords: adolescent; child; oral hygiene; oral hygiene index; orphanages; motivation.

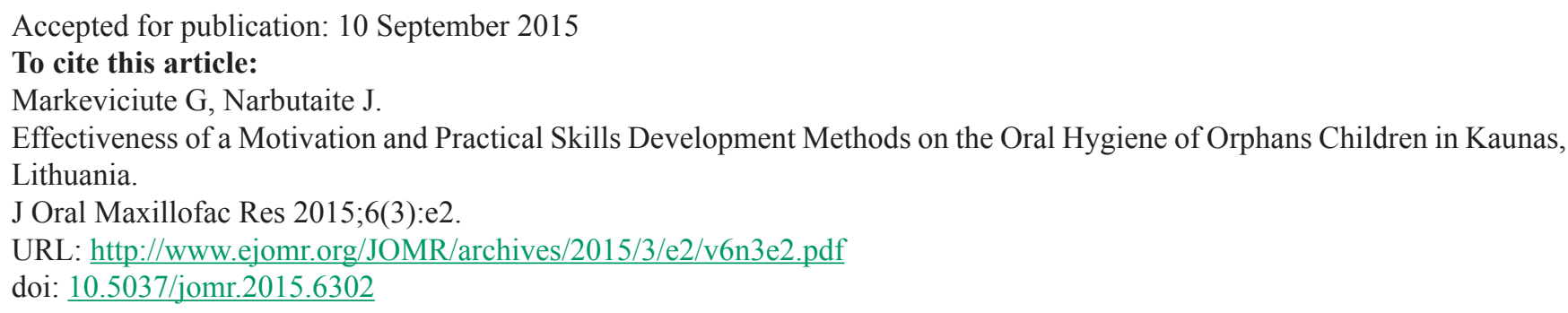




\section{INTRODUCTION}

Oral health is fundamental to general health and well being, significantly impacting on quality of life [1]. Untreated oral diseases progress with time. Bad oral health may have a negative impact on appearance, ability to eat, communication with people, on daily tasks at work, home or school [2]. Children with poor oral health suffer from dental pain more often, miss school and perform poorly in school [3]].

Good oral hygiene is recognized as a key factor for oral disease prevention. Regular tooth brushing with fluoride toothpaste can reduce dental conditions of tooth decay and periodontal disease. Mechanical removal of dental plaque is important factor which helps to control periodontal diseases [4].

A survey, performed in Lithuania among 373 adolescents showed that majority of them $(73.7 \%)$ brush teeth two times a day or more often. Only $3.2 \%$ said to be brushing teeth less than once a day. The importance of regular tooth brushing in oral health indicated $97.6 \%$ of respondents [ $\underline{5}$ ].

The results of international survey, among 11, 13 and 15 year-old schoolchildren, regarding how often they brush their teeth, showed that only about $40 \%$ of boys $(42 \%-11,40 \%-13,40 \%-15$ year-olds) and more than a half of the girls $(52 \%-11,62 \%-13$, $65 \%$ - 15 year-olds) in Lithuania brush their teeth more often than once a day [6]. The study among 586 schoolchildren aged 7,12 and 15 years in Kaunas (Lithuania) showed that $64.5 \%$ of participants, brushing their teeth daily, had a good oral hygiene and 19\% - fair [7].

Children's knowledge and skills of oral hygiene mostly depends on habits and approach of their parents and their attitude regarding oral hygiene of their children [8,9]. Children living in child care homes do not get appropriate information about health care and oral hygiene from their parents. It becomes a responsibility of supervisors to teach children by providing them necessary knowledge and encouraging kids to take a better care of their oral hygiene. Studies has shown that orphans have fair oral hygiene because of limited education and access to services [10-12].

Knowledge about proper oral hygiene is better perceived through motivation, practical skills development and involvement of parents $[9,10,13]$. Studies in different countries showed significant improvement, progress in oral health results after practical and motivational interventions [2,9].

We hypothesized that child care home children's tooth brushing habits and oral hygiene quality can be influenced by motivation and simple individual instructions.
The aim of this study was to evaluate and compare two different oral health promotion methods as well as outcome of both methods on a quality of oral hygiene.

\section{MATERIAL AND METHODS Study design and sampling}

The present study was conducted from September 15, 2013 to December 15, 2013. The study was designed as a 3 month intervention study involving children and adolescents from two child care homes in Kaunas, Lithuania. The data included the children's clinical plaque accumulation examinations at baseline and at study end, as well as a self-administered questionnaire for the participants at baseline and at study end.

Two child care homes were selected out of five in the city as the remaining three lacked participants. The number of children provided by the two child care homes was almost equal and both institutions were willing to participate. In total, 68 participants (32 of practical application group and 36 of motivation group) were enrolled into this study (Figure 1). Age was categorized in 2 categories based on maturity and distribution of the participants. Age, gender of the participants in the motivation and practical application groups is presented in Table 1.

The protocol was approved by the Ethics Committee of Lithuanian University of Health Sciences, Kaunas, Lithuania. Participation in the study was voluntary and the participants were informed about study details before. Caregiver's written consent was obtained prior study started.

\section{Clinical examination}

For both groups participants, a similar clinical plaque accumulation examination was conducted at baseline and at the study end, using a dental mirror, a sterile probe, and a portable dental equipment lamp in the health office at the care home before lunch. Recordings on plaque accumulation were performed based on a plaque index (PLI) [14]. Four gingival areas (distal, facial, mesial and lingual) were recorded for each tooth to indicate the child's oral hygiene status. Dental plaque was recorded as 1) no plaque, plaque on gingival margins and adjacent area of the tooth; 2) clearly visible plaque on the tooth and gingival margin; 3) soft thick layer of plaque on the tooth and gingival margin with scores correspondingly $0,1,2,3$. Scores for each were totalled and divided by 4 . Scores for each tooth were added and divided by the number of the teeth examined. 


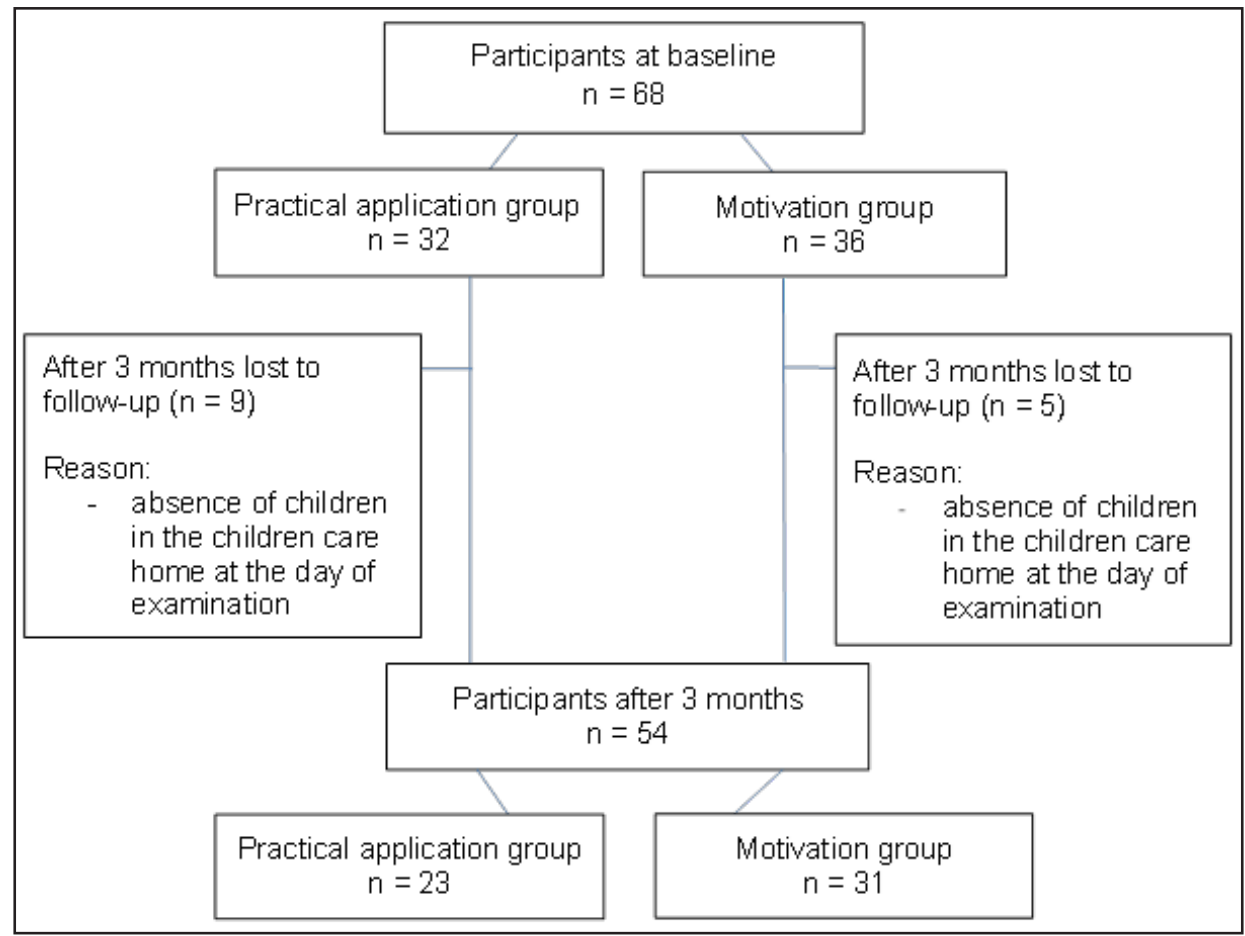

Figure 1. Flow diagram of intervention participants at baseline and after 3 months.

Table 1. Distribution of participants according to age, gender and intervention group type

\begin{tabular}{|c|c|c|c|c|c|c|c|c|}
\hline \multirow{3}{*}{ Group type } & \multicolumn{4}{|c|}{ At baseline $(n=68)$} & \multicolumn{4}{|c|}{ After 3 months intervention $(n=54)$} \\
\hline & \multicolumn{8}{|c|}{$\mathbf{N}(\%)$} \\
\hline & Boys & Girls & $\begin{array}{c}7-12 \\
\text { year-olds }\end{array}$ & $\begin{array}{c}13-17 \\
\text { year-olds }\end{array}$ & Boys & Girls & $\begin{array}{c}7-12 \\
\text { year-olds }\end{array}$ & $\begin{array}{c}13-17 \\
\text { year-olds }\end{array}$ \\
\hline Motivation $(n=36)$ & $23(63.9)$ & $13(36.1)$ & $16(44.4)$ & $20(55.6)$ & $21(67.7)$ & $10(32.3)$ & $14(45.2)$ & $17(54.8)$ \\
\hline Practical application $(n=32)$ & $18(56.3)$ & $14(43.8)$ & $19(59.4)$ & $13(40.6)$ & $10(43.5)$ & $13(56.5)$ & $15(65.2)$ & $8(34.8)$ \\
\hline P value & \multicolumn{2}{|c|}{0.52} & \multicolumn{2}{|c|}{0.219} & \multicolumn{2}{|c|}{0.075} & \multicolumn{2}{|c|}{0.144} \\
\hline
\end{tabular}

$\mathrm{P}$ value considered significant when $\mathrm{P}>0.05$ by Chi-square test $\left(\chi^{2}\right)$.

Plaque scores were calculated for both baseline and outcome examinations.

The final result was obtained by adding the total surfaces with plaque and dividing this by total number of teeth examined.

The baseline clinical examination was conducted by one of the authors (G. M.). For the outcome examination, another dentist, one not involved in the present study procedures and blind to group assignment was involved. Subsequently, a calibration was carried out on a separate group of 10 children. Each was examined by one of the examiners and then re-examined by the other examiner within 1 hour. This procedure resulted in an inter-examiner reliability with a Kappa value of 0.76 , representing an excellent agreement between examiners.

\section{Questionnaire}

Children were asked to complete a self-administered questionnaire at the baseline and at the study end. Response rate was $100 \%$ and $79 \%$, respectively. Questionnaire inquired about oral hygiene habits, self-perception, dental attendance, dietary habits. At baseline, 19 item questionnaire was used to assess the oral hygiene knowledge and practices and at the end 21. Two questions were added in order to know, whether the programme was beneficial and if the respondents got to know something new.

\section{Interventions}

Two kinds of intervention were implemented, one motivation, another practical application. Approximately, one week after data collection at baseline, interventions began, and the follow-up examinations occurred 3 month later. The execution of the intervention was monitored by one of the authors (G. M.) through visits to the child care homes and discussions with staff. 


\section{Motivation group}

This intervention was applied in children care home by means of five lectures prepared by one of the authors (G. M.). Lectures covered different topics: 1) tooth structure and development (lecture included tooth brushing demonstration); 2) risk factors of oral diseases, dental caries development; 3) how to manage in the dental clinic, treatment of dental caries, prevention; 4) dental plaque, as a risk factor of gingivitis, 5) diet counselling. Lectures contained: comprehensive well-known oral health information of tooth structure, development, functioning, the aetiology of common oral diseases - dental caries, gingival diseases; preventability of oral diseases and the ways to keep the mouth healthy by recommending twice-daily tooth brushing, use of fluoride toothpaste and restricting sugary snacking. Lectures were read once every three weeks and used simple language and explained scientific issues plainly and clearly to make it easy for children to understand.

\section{Practical application group}

This intervention was applied by means of practical teaching children once a week. One of the authors (G. M.) every week for 3 month period was visiting children in child care home and supervised how they brushing teeth. One lecture (dental caries risk factors, prevention of tooth decay, tooth brushing demonstration) before starting intervention was delivered to children and staff of the children care home. The participants were instructed on how to carry out effective oral hygiene.

\section{Evaluation of the intervention}

After 3 month 54 children were examined clinically and scored for PLI. The reasons for the $20.6 \%$ not attendance was absence of children in the children care home at the day of examination (Figure 1). The outcome measures of the present study was changes in plaque scores. Changes in PLI calculated as differences in score of plaque from baseline to the outcome examination. A positive value indicated improvement in plaque accumulation reducing.

\section{Statistical analysis}

Statistical data analysis was conducted using the statistical Package for Social Sciences (SPSS) Version 20 for Windows. The data were analysed using descriptive statistics and verified statistical

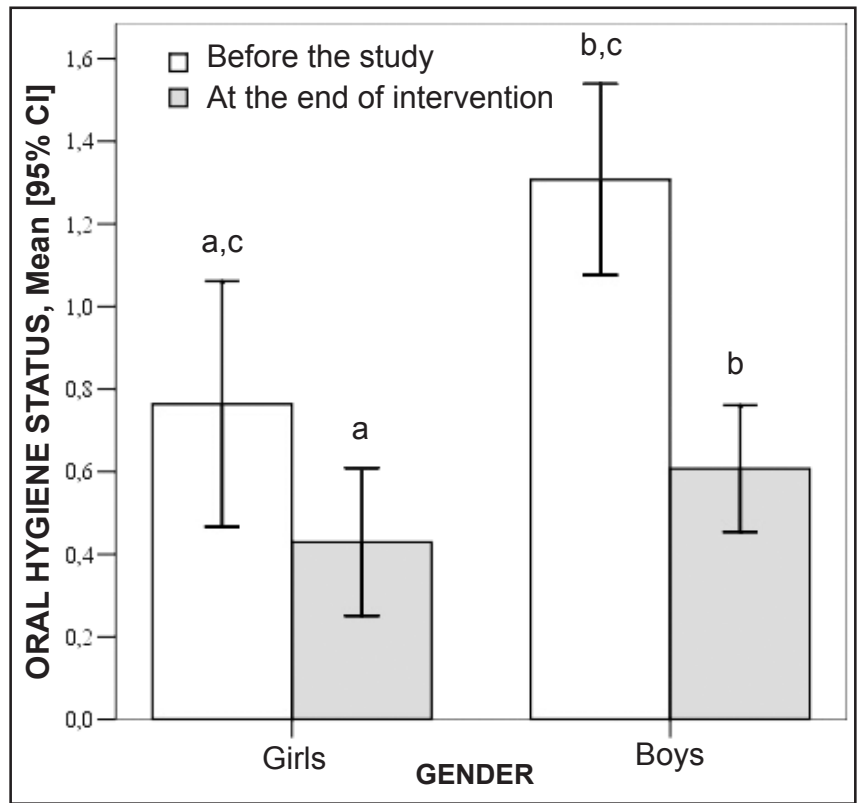

Figure 2. Oral hygiene status by gender before and after intervention in motivation group.

${ }^{a} \mathrm{P}<0.05$; Student's t-test for difference between girls.

${ }^{\mathrm{b}} \mathrm{P}<0.05$; Student's t-test for difference between boys.

${ }^{\mathrm{c}} \mathrm{P}<0.05$; Student's t-test for difference between girls and boys at baseline.

$\mathrm{CI}=$ Confidence interval.

hypotheses about average rate differences and signs of mutual interdependence. Parametric data were expressed as mean and standard deviation (M [SD]). $\mathrm{P}$ value less than 0.05 was regarded to indicate statistical significance. Chi-square test $\left(\chi^{2}\right)$ or Fisher's exact test was used to compare qualitative variables based on cross tabulation. For comparing averages of quantitative variables between groups, Student's t-test or nonparametric Mann-Whitney test was used. Spearman's rho correlation coefficient was used to evaluate oral hygiene status dependence on age. Kappa coefficient was used to compare two examiners coincidence of survey data.

\section{RESULTS}

The oral hygiene status of the orphans before intervention was $1.11(0.46)$. All children had a plaque on at least one tooth in both groups: motivation 1.14 (0.51) and practical application $1.08(0.4)(\mathrm{P}=0.58)$. Older children had poorer oral hygiene, however no statistically significant difference between age groups determined $(\mathrm{P}=0.13)$. Comparisons between different intervention and age groups are in Table 2. According to gender significant difference between motivation (63.9\% boys, $36.1 \%$ girls) and practical application groups (56.3\% boys, $43.8 \%$ girls) was not found $(\mathrm{P}=0.52)($ Table 1). 
Table 2. Distribution of study participants' oral hygiene status according to intervention type and age groups

\begin{tabular}{|c|c|c|c|c|}
\hline & 7 - 12 year-olds & 13 - 17 year-olds & Total & \multirow{2}{*}{ P value } \\
\hline & \multicolumn{3}{|c|}{ Mean (SD) } & \\
\hline \multicolumn{5}{|l|}{ Oral hygiene status at baseline } \\
\hline Motivation group & $1.09(0.55)$ & $1.18(0.5)$ & $1.14(0.51)$ & \multirow{3}{*}{$\mathrm{P}=0.58^{\mathrm{a}}$} \\
\hline Practical application group & $0.98(0.33)$ & $1.23(0.46)$ & $1.08(0.4)$ & \\
\hline Total & $1.03(0.44)$ & $1.20(0.48)$ & $1.11(0.46)$ & \\
\hline P value & \multicolumn{3}{|c|}{$\mathrm{P}=0.13^{\mathrm{b}}$} & \\
\hline \multicolumn{5}{|c|}{ Oral hygiene status after 3 months intervention } \\
\hline Motivation group & $0.53(0.31)$ & $0.56(0.33)$ & $0.55(0.32)$ & \multirow{3}{*}{$\mathrm{P}<0.001^{\mathrm{a}}$} \\
\hline Practical application group & $0.15(0.13)$ & $0.25(0.43)$ & $0.19(0.27)$ & \\
\hline Total & $0.34(0.3)$ & $0.46(0.39)$ & $0.40(0.35)$ & \\
\hline P value & \multicolumn{3}{|c|}{$\mathrm{P}=0.19^{\mathrm{b}}$} & \\
\hline
\end{tabular}

${ }^{\mathrm{a}}$ Comparisons between motivation and practical application groups.

${ }^{b}$ Comparisons between age groups within motivation and practical application groups.

$P$ value by parametric Student's t-test.

$\mathrm{SD}=$ standard deviation.

\section{Gingival health at baseline}

Oral hygiene status between genders was statistically significant $(\mathrm{P}=0.007)$. Girls oral hygiene status 0.86 $(0.36)$ was significantly better than boys $1.28(0.45)$ $(\mathrm{P}<0.001)$. Significantly better oral hygiene status of the girls was found in both groups: motivation group (girls 0.82 [0.39], boys 1.33 [0.49]) $(\mathrm{P}=0.003)$ (Figure 2) and practical application group (girls 0.9 [0.33], boys $1.23[0.4])(\mathrm{P}=0.03)$ (Figure 3).

\section{Questionnaire}

All orphans responded to the questionnaire before the examination. Sixty percent $(n=21)$ of $7-12$ year-olds and $39.4 \%(n=13)$ of $13-17$ year-olds, reported that brush their teeth twice a day (Table 3). No significant difference between age groups was determined $(\mathrm{P}=0.09)$. There were more boys $(61 \%)$ than girls $(33 \%)(\mathrm{P}=0.03)$ who brush their teeth less than twice a day. Dental floss was used by $8.8 \%(n=3)$ of $7-12$ year-olds and $9.1 \%(n=3)$ of 13 - 17 year-olds $(P=0.97)$. Satisfied with their oral health answered $74.3 \%(n=26)$ of $7-12$ year-olds,

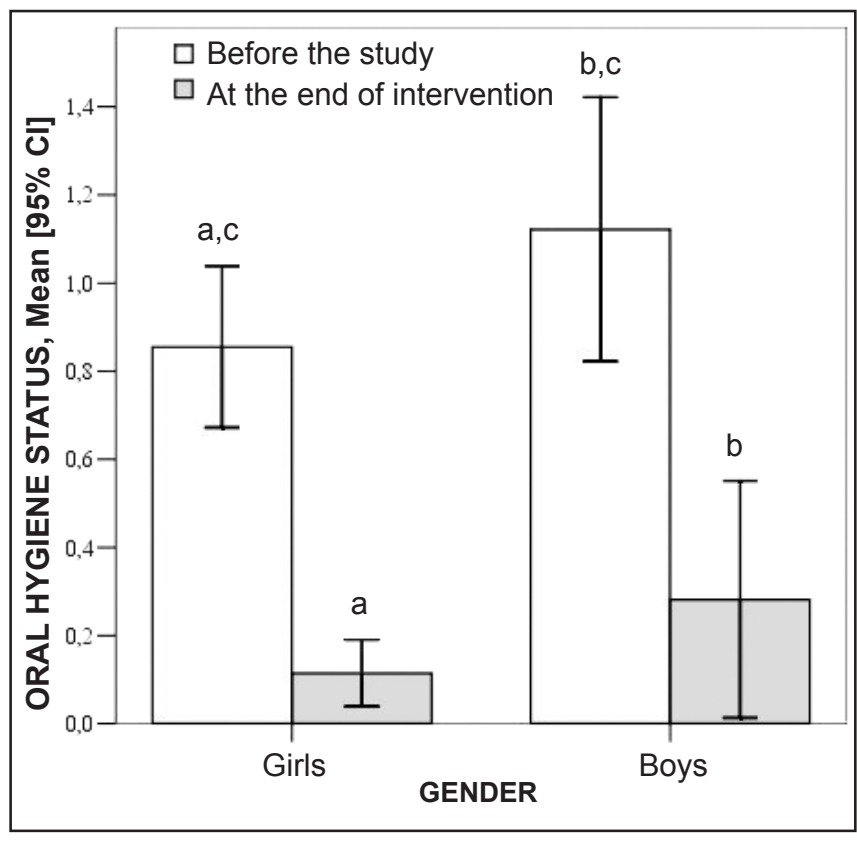

Figure 3. Oral hygiene status by gender before and after intervention in practical application group.

${ }^{a} \mathrm{P}<0.05$; Student's t-test for difference between girls.

${ }^{\mathrm{b}} \mathrm{P}<0.05$; Student's t-test for difference between boys.

cP $<0.05$; Student's t-test for difference between girls and boys at baseline.

$\mathrm{CI}=$ Confidence interval .

Table 3. Participants opinion about their oral health before and after intervention

\begin{tabular}{|c|c|c|c|c|c|}
\hline \multirow{3}{*}{ Survey questions } & \multirow{3}{*}{ Given answers } & \multicolumn{2}{|c|}{7 - 12 year-olds } & \multicolumn{2}{|c|}{13 - 17 year-olds } \\
\hline & & At baseline & $\begin{array}{l}\text { After } 3 \text { months } \\
\text { intervention }\end{array}$ & At baseline & $\begin{array}{l}\text { After } 3 \text { months } \\
\text { intervention }\end{array}$ \\
\hline & & \multicolumn{4}{|c|}{$\%(n)$} \\
\hline \multirow{2}{*}{ How often you brush your teeth? } & 2 times a day & $60(21)$ & $58.6(17)$ & $39.4(13)$ & $56(14)$ \\
\hline & $<2$ times a day & $40(14)$ & $41.4(12)$ & $60.6(20)$ & $44(11)$ \\
\hline \multirow{2}{*}{ Do you floss your teeth? } & No & $91.2(31)$ & $86.2(25)$ & $90.9(30)$ & $88(22)$ \\
\hline & Yes & $8.8(3)$ & $13.8(4)$ & $9.1(3)$ & $12(3)$ \\
\hline \multirow{2}{*}{ Are you satisfied with your oral health? } & No & $25.7(9)$ & $13.8(4)$ & $42.4(14)$ & $32(8)$ \\
\hline & Yes & $74.3(26)$ & $86.2(25)$ & $57.6(19)$ & $68(17)$ \\
\hline \multirow{2}{*}{$\begin{array}{l}\text { Do you think that regular tooth brushing } \\
\text { can keep your teeth healthy? }\end{array}$} & No & $17.1(6)$ & $10.3(3)$ & $3(1)$ & $20(5)$ \\
\hline & Yes & $82.9(29)$ & $89.7(26)$ & $97(32)$ & $80(20)$ \\
\hline
\end{tabular}


and $57.6 \%(n=19)$ of $13-17$ year-olds $(P=0.15)$. Regular tooth brushing is important in having healthy teeth stated $82.9 \%(\mathrm{n}=29)$ of $7-12$ year-olds and $97 \%(\mathrm{n}=32)$ of $13-17$ year-olds $(\mathrm{P}=0.06)($ Table 3$)$. Significantly more boys, $75.6 \%(\mathrm{n}=31)$, were satisfied with their oral health, than girls, $51.9 \%$ (n $=14)(\mathrm{P}=0.04)$. Within the last 12 months: $77.1 \%$ $(\mathrm{n}=27)$ children of age $7-12$ years and $90.9 \%(\mathrm{n}$ $=30$ ) children of age $13-17$ years, visited dentist. Most of the orphans visited dentist for check up $45.2 \%(\mathrm{n}=28)$ while few of respondents for orthodontic treatment $4.8 \%(\mathrm{n}=3)$. The children were asked how often soft drinks and sweets they consumed during a week: $76.4 \%(\mathrm{n}=52)$ children reported that they drank soft drinks and $89.6 \%$ $(n=60)$ ate sweets at least once a week.

\section{Gingival health after 3 months intervention}

After 3 months intervention oral hygiene improved significantly in both groups $0.4(0.35)(\mathrm{P}<0.001)$. Practical application group $0.19 \quad(0.27)$ showed significantly better oral hygiene than motivation group $0.55(0.32)(\mathrm{P}<0.001)$. Before the examination, the difference was not significant $(\mathrm{P}=0.58)$ (Table 2).

Oral hygiene status in different age groups was not statistically significant after intervention $(P=0.19)$, however younger children group demonstrated better oral hygiene, the same tendency as at baseline (Table 2).

Girls showed significantly better oral hygiene than boys $(\mathrm{P}=0.005)$. The same tendency was observed as at baseline (Figure 2 - 3).

Before the study, the oral hygiene status of boys (1.28 [0.45]) was significantly lower than girls $(0.86[0.36])$ $(\mathrm{P}<0.001)$. In the motivation group: girls $0.82(0.39)$, boys $1.33(0.49)(\mathrm{P}=0.003)$; and practical application group: girls $0.90(0.33)$, boys $1.23(0.4)(\mathrm{P}=0.03)$. At the end of intervention, the difference was significant in motivation group girls $0.33(0.35)$, boys $0.7(0.0)$ $(\mathrm{P}=0.018)$ and became insignificant in practical application group girls $0.74(0.3)$, boys $0.84(0.37)$ $(\mathrm{P}=0.556)$ (Figure 2 - 3).

After the study oral hygiene improvement was higher for boys $0.75(0.39)$ than girls $0.56(0.37)$, but statistically insignificant $(\mathrm{P}=0.09)$.

\section{Questionnaire after 3 months intervention}

Children's tooth brushing habits did not change statistically significant between both training groups $(P=0.91)$ and between age groups $(P=0.85)$ after the study. Tooth brushing frequency statistically significantly changed among girls in comparison with the boys $(\mathrm{P}<0.001)$.

After the study, significantly more girls $(91.3 \%)$ were satisfied with their oral health than boys $(67.7 \%)$ $(\mathrm{P}=0.04)$. Before the study significantly more boys $(75.6 \%)$ were satisfied with their oral health $(51.9 \%)$ $(\mathrm{P}=0.04)$.

After intervention 7 - 12 year-olds were more satisfied with their oral health than 13 - 17 year-olds, but significant difference was not found $(\mathrm{P}=0.11)$ (Table 3). After the study, children from practical application group were more satisfied with their oral health than before study, but statistically significant difference were not found $(\mathrm{P}=0.16)$.

Comparing results of questionnaire surveys at baseline and after intervention on use of soft drinks, a statistically significant decrease of their use was noticed in both intervention groups $(\mathrm{P}=0.004)$. The habits of sweets use did not change significantly $(\mathrm{P}=0.34)$ during the surveys.

After 3 months, children were asked what they thought about the programme: $83 \%$ they have learned something new and $88.7 \%$ found that the program was useful.

\section{DISCUSSION}

Results of the present study showed that oral health promotion based on motivation and practical skills development is effective in improving oral hygiene among orphan children. It has been found significant improvement of oral hygiene in both practical application and motivation groups. Most of the children at baseline demonstrated good or fair oral hygiene and after three months - excellent or good (Table 2).

Oral hygiene of all children at a baseline was 1.11 (0.46) and significantly better among girls than the boys $(\mathrm{P}<0.001)$. Our findings are in accordance with the findings of the other study performed in Nigeria among orphans [10]. Other study from India conducted by Khare et al. [12], showed that boys had significantly higher caries prevalence than girls. Probably because of boys being more ignorant about their health.

The findings of our study showed that younger boys in both groups had better oral hygiene before intervention and after three month. Study by Mahesh et al. [15], presented similar results where older children had lower scores.

It is well known that the best way to remove dental plaque is a proper regular tooth brushing including hardly reachable surfaces of the teeth. It also very important to apply a proper method since children 
differ in their abilities of brushing and that is dependent on their experience as well as physical and neurological development [16-18]. It has been proven that brushing skills get better with age and that the duration of brushing is significant for oral hygiene of children as well [19].

Results of questionnaire survey conducted in Lithuania has showed that $73.7 \%$ of teenagers brush their teeth at least twice a day or more often []ㅡ. Half of our study participants $(50.7 \%)$ reported brushing their teeth twice a day while the rest of children doing this only once a day or less. The explanation of such low number of regular brushers is that children are not living in families. Several studies has found that children's knowledge and skills of oral hygiene mostly depends on their parents attitude regarding oral hygiene of their children $[\underline{8}, 9,20]$. Taking into account statistical results from Sweden, it is noticeable that 6 year-old children brush their teeth in a significantly shorter amount of time compared to children from other age groups (6 - 12 year-olds were measured). Brushing their teeth for less than 1 minute indicated $21 \%$ of kids. Brushing their teeth at least twice a day or more often mentioned $91 \%$ of children [21]. Results from another study showed, that only $32.8 \%$ of kids brush their teeth at least twice a day. None of the kids said to be cleaning their teeth more often [22].

Various studies provided similar results about oral hygiene of boys and girls, who is better or dedicate more time to take care of their dental health. Our survey showed a significant difference in oral hygiene between genders $(P=0.007)$. Girls oral hygiene status $0.86(0.36)$ was significantly better than boys 1.28 $(0.45)(\mathrm{P}<0.001)$. It was also noticed that there are more boys $(61 \%)$ than girls $(33 \%)(\mathrm{P}=0.03)$ who brush their teeth less than twice a day. The results are in accordance with the findings of study in Finland [23]. Considering the results of the study on dental caries prevalence and treatment needs it is also clearly that girls are more concern about their oral health than boys [12].

More effective was practical skills development educational method than motivation. So it could be recommended as an educational tool for teenagers with the emphasis on boys education. Based on the findings of the study in Lithuania, it should be stated that frequency of tooth brushing does not always mean better oral hygiene. The quality of tooth brushing is more important [?].

After three month period, the statistically significant increase of good oral hygiene was registered in both groups $(\mathrm{P}<0.001)$. Based on our findings seems that both types of education are effective.
However group of practical application provided better results. It is also known that practice without sufficient motivation can show only temporarily positive results [13]. Despite fact that motivation group showed less improvement, probably they can have more permanent effect in the long term in comparison with practical application group. D'cruz and Aradhya [24] state that lectures may increase theoretical knowledge and practical skills to children, however lectures together with practical means shows even better results. Combination of both methods: practical and motivational teaching for the benefits to be greater and longer lasting.

During a period of 3 months, the positive changes in oral hygiene were found and evaluated. The authors of a study that was conducted in India came to a conclusion that short term research and educational programs, taking a period of 3 months, are effective to measure positive changes in oral hygiene [25]. The 3 month research program performed in Iran, showed increased quality of oral hygiene not only in intervention group, but control group as well [9].

Comparing results of the two questionnaires at baseline and at the end significantly less children reported using soft drinks in both groups $(\mathrm{P}=0.004)$. Another survey provides the same results. Before the survey sweet drinks actively brought to schools $22.4 \%$ of kids and $13.3 \%$ of kids after it. A statistically significant change was estimated $(\mathrm{P}=0.01)$ [22] The habits of confectionary use did not change significantly $(\mathrm{P}=0.34)$ during the surveys [22]

Health educational programs are as an effective tool in children motivation to perform oral hygiene were found by the different authors $[\underline{9}, \underline{13}, \underline{16}, \underline{19}]$. It order to obtain/gain best possible results and have a long term effect, those should include and stimulate collaboration between school personal, medical staff and parents. Good results the previous programs were reached when oral hygiene was regularly performed at home as well. Teaching and explaining the importance of oral hygiene improves the state of hygiene temporally during the process of program or a short time afterwards [25]. The present program involved not only the children but orphanage personnel as well. We hope that motivated personnel will help to continue children motivation and supervision with long term positive benefits to the program.

After three month, statistically significant improvement of oral hygiene was observed, which shows that motivational, as well as practical, programs, stimulating care of oral health, are efficient in complementing oral hygiene, but before and after results of anonymous survey did not provide meaningful results. It is safe to say that kids need more than 3 months to absorb 
information and change attitude. It is also clear that there was a lack of motivation in practice group for kids to change their mindset. It is stated, that practical teaching without motivation may be short-termed [13]. Thereof, we may guess that improvement of oral hygiene in motivation group, despite being less visible, may have longer lasting effects than those of practical application group. Teaching programs should include both practical and motivational teaching to have the best possible outcome for the longest possible time.

Years spent at school are greatly influential for human being, meaning that habits of oral health, as well as other convictions and attitude, are developed for the rest of one's life [1] and one of the main and most efficient means of teaching kids to properly take care of their oral hygiene are oral hygiene educational programs in schools $[\underline{10}, 13]$.

\section{CONCLUSIONS}

Educational programmes are effective to improve the oral hygiene, especially when they're based on practical skills training.

\section{ACKNOWLEDGMENTS AND DISCLOSURE STATEMENTS}

The authors declare that they have no conflict of interests.

\section{REFERENCES}

1. World Health Organization. Oral Health Promotion: An Essential Element of a Health-Promoting School. WHO information series on school health, Doc 11. Geneva: WHO; 2003. p. 65. [URL: http://www.who.int/oral_health/media/ en/orh_school_doc11.pdf]

2. U.S. Department of Health and Human Services. Oral Health in America: A Report of the Surgeon General. Rockville (MD): U.S. Department of Health and Human Services, National Institute of Dental and Craniofacial Research, National Institutes of Health; 2000. p. 322. [URL: http://profiles.nlm.nih.gov/ps/access/NNBBJT.pdf]

3. Jackson SL, Vann WF Jr, Kotch JB, Pahel BT, Lee JY. Impact of poor oral health on children's school attendance and performance. Am J Public Health. 2011 Oct;101(10):1900-6. [Medline: 21330579] [PMC free article: 3222359] [doi: 10.2105/AJPH.2010.200915]

4. Public Health England. Delivering better oral health: an evidence-based toolkit for prevention. 3rd ed. London: Public Health England. 2014 Jun. p.102. [URL: https://www.gov.uk/government/uploads/system/uploads/attachment data/ file/367563/DBOHv320140CTMainDocument 3.pdf]

5. Saveljevaite J. [High school students' mindset to professional oral hygiene services] . Master's thesis. Lithuanian University of Health Sciences. Kaunas, 2010. Lithuanian. [URL: http://vddb.library.lt/fedora/get/LT-eLABa-0001:E.02 2010 D_20100621_093625-00295/DS.005.0.01.ETD]

6. Currie C, Zanotti C, Morgan A, Currie D, Looze M, Roberts C, Samdal O, Smith ORF, Barnekow V. Social determinants of health and well-being among young people. Health Behaviour in School-aged Children (HBSC) study: international report from the 2009/2010 survey. Copenhagen: WHO Regional Office for Europe; 2012. p. 271.

7. Milciuviene S, Matulaitiene Z, Narbutaite J, Vaitkeviciene V, Bendoraitiene E, Timofejeva I. [Dental status among schoolchildren in Kaunas and analysis of oral health care]. Medicina (Kaunas). 2006;42(5):413-23. Lithuanian. [Medline: 16778470]

8. Bozorgmehr E, Hajizamani A, Malek Mohammadi T. Oral health behavior of parents as a predictor of oral health status of their children. ISRN Dent. 2013 May 8;2013:741783. [Medline: 23738088] [PMC free article: 3664493] [doi: $10.1155 / 2013 / 741783$ ]

9. Saied-Moallemi Z, Virtanen JI, Vehkalahti MM, Tehranchi A, Murtomaa H. School-based intervention to promote preadolescents' gingival health: a community trial. Community Dent Oral Epidemiol. 2009 Dec;37(6):518-26. [Medline: 19694774] [doi: 10.1111/j.1600-0528.2009.00491.x]

10. Ojahanon PI, Akionbare O, Umoh AO. The oral hygiene status of institution dwelling orphans in Benin City, Nigeria. Niger J Clin Pract. 2013 Jan-Mar;16(1):41-4. [Medline: 23377468] [doi: 10.4103/1119-3077.106732]

11. Muralidharan D, Fareed N, Shanthi M. Comprehensive dental health care program at an orphanage in Nellore district of Andhra Pradesh. Indian J Dent Res. 2012 Mar-Apr;23(2):171-5. [Medline: 22945705] [doi: 10.4103/0970-9290.100421]

12. Khare V, Koshy A, Rani P, Srilatha S, Kapse SC, Agrawal A. Prevalence of dental caries and treatment needs among the orphan children and adolescents of Udaipur district, Rajasthan, India. J Contemp Dent Pract. 2012 Mar 1;13(2):182-7. [Medline: 22665745] [doi: 10.5005/jp-journals-10024-1118] 
13. Neamatollahi H, Ebrahimi M, Talebi M, Ardabili MH, Kondori K. Major differences in oral health knowledge and behavior in a group of Iranian pre-university students: a cross-sectional study. J Oral Sci. 2011 Jun;53(2):177-84. [Medline: 21712622] [doi: 10.2334/josnusd.53.177]

14. Löe H, Silness J. Periodontal disease in pregnancy. I. Prevalence and severity. Acta Odontol Scand. 1963 Dec;21:533-51. [Medline: 14121956] [doi: 10.3109/00016356309011240]

15. Mahesh Kumar P, Joseph T, Varma RB, Jayanthi M. Oral health status of 5 years and 12 years school going children in Chennai city--an epidemiological study. J Indian Soc Pedod Prev Dent. 2005 Mar;23(1):17-22. [Medline: 15858301] [doi: 10.4103/0970-4388.16021]

16. Das UM, Singhal P. Tooth brushing skills for the children aged 3-11 years. J Indian Soc Pedod Prev Dent. 2009 AprJun;27(2):104-7. [Medline: 19736503] [doi: 10.4103/0970-4388.55335]

17. Stephen Wei HY. Pediatric dentistry total patient care. Mechanical and chemical plaque control. Philadelphia: Lea \& Febiger; 1988. p. 23-46.

18. Sharma S, Yeluri R, Jain AA, Munshi AK. Effect of toothbrush grip on plaque removal during manual toothbrushing in children. J Oral Sci. 2012;54(2):183-90. [Medline: 22790411] [doi: 10.2334/josnusd.54.183]

19. Pujar P, Subbareddy VV. Evaluation of the tooth brushing skills in children aged 6-12 years. Eur Arch Paediatr Dent. 2013 Aug;14(4):213-9. [Medline: 23737009] [doi: 10.1007/s40368-013-0046-3]

20. Gavin A, O’Higgins S, Brennan G, Clerkin P, Róiste A, Fitzpatrick C, Kelly C, Molcho M, Walker L, Gabhainn NS. Oral Hygiene among schoolchildren in Ireland. HBSC Ireland Research Factsheet No. 7. 2006. [URL: http://www.nuigalway.ie/hbsc/documents/fs 7 _2006 july09.pdf]

21. Sandström A, Cressey J, Stecksén-Blicks C. Tooth-brushing behaviour in 6-12 year olds. Int J Paediatr Dent. 2011 Jan;21(1):43-9. [Medline: 20659179] [doi: 10.1111/j.1365-263X.2010.01080.x]

22. Livny A, Vered Y, Slouk L, Sgan-Cohen HD. Oral health promotion for schoolchildren - evaluation of a pragmatic approach with emphasis on improving brushing skills. BMC Oral Health. 2008 Jan 31;8:4. [Medline: 18237389] [PMC free article: 2253522] [doi: 10.1186/1472-6831-8-4]

23. Halonen H, Pesonen P, Seppä L, Peltonen E, Tjäderhane L, Anttonen V. Outcome of a community-based oral health promotion project on primary schoolchildren's oral hygiene habits. Int J Dent. 2013;2013:6. [PMC free article: 3844209 ] [doi: $10.1155 / 2013 / 485741]$

24. D'Cruz AM, Aradhya S. Impact of oral health education on oral hygiene knowledge, practices, plaque control and gingival health of 13- to 15-year-old school children in Bangalore city. Int J of Dent Hyg. 2013;11(2): 126-133. [Medline: 22747831] [doi: 10.1111/j.1601-5037.2012.00563.x]

25. Bhardwaj VK, Sharma KR, Luthra RP, Jhingta P, Sharma D, Justa A. Impact of school-based oral health education program on oral health of 12 and 15 years old school children. J Educ Health Promot. 2013 Jul;2:33. [PMC free article: $\underline{3778644]}$ [doi: 10.4103/2277-9531.11582]

\section{To cite this article:}

Markeviciute G, Narbutaite J.

Effectiveness of a Motivation and Practical Skills Development Methods on the Oral Hygiene of Orphans Children in Kaunas, Lithuania.

J Oral Maxillofac Res 2015;6(3):e2.

URL: http:/www.ejomr.org/JOMR/archives/2015/3/e2/v6n3e2.pdf

doi: 10.5037/jomr.2015.6302

Copyright (C) Markeviciute G, Narbutaite J. Published in the JOURNAL OF ORAL \& MAXILLOFACIAL RESEARCH (http://www.ejomr.org), 30 September 2015.

This is an open-access article, first published in the JOURNAL OF ORAL \& MAXILLOFACIAL RESEARCH, distributed under the terms of the Creative Commons Attribution-Noncommercial-No Derivative Works 3.0 Unported License, which permits unrestricted non-commercial use, distribution, and reproduction in any medium, provided the original work and is properly cited. The copyright, license information and link to the original publication on (http://www.ejomr.org) must be included. 